\title{
CCG funding Criteria for ENT Procedures of Limited Clinical Effectiveness.
}

Conybeare A, Isles M, University Hospitals of North Midlands NHS Trust

\section{Background}

In July 2016, North Staffordshire CCG introduced criteria for funding ENT procedures of limited clinical effectiveness. The criteria were based on national standards of practice and the Trust had to provide evidence that the standards were being met.

\section{Objectives}

We wished to investigate the impact of these criteria on local ENT listing practice, as well as interrogate the adherence of the criteria to the national standards.

\section{Methods}

This was a retrospective audit analyzing ENT surgical activity, prior to the introduction of the criteria, then 6 and 12 months after. The clinic letter was looked at for evidence of compliance.

\section{Results}

Only tonsillectomy and adenotonsillectomy rates were reduced after the introduction of the CCG criteria. Although based on national guidelines, the forms demonstrated many deviations from the original clinical guidelines, for example splitting the Grommet criteria statement into two parts that no longer made sense.

\section{Conclusion}

The forms were not found to be fit for purpose. The effect on tonsillectomies and adenotonsillectomies could be explained by other variables (loss of Locum Consultant) over the same time period.

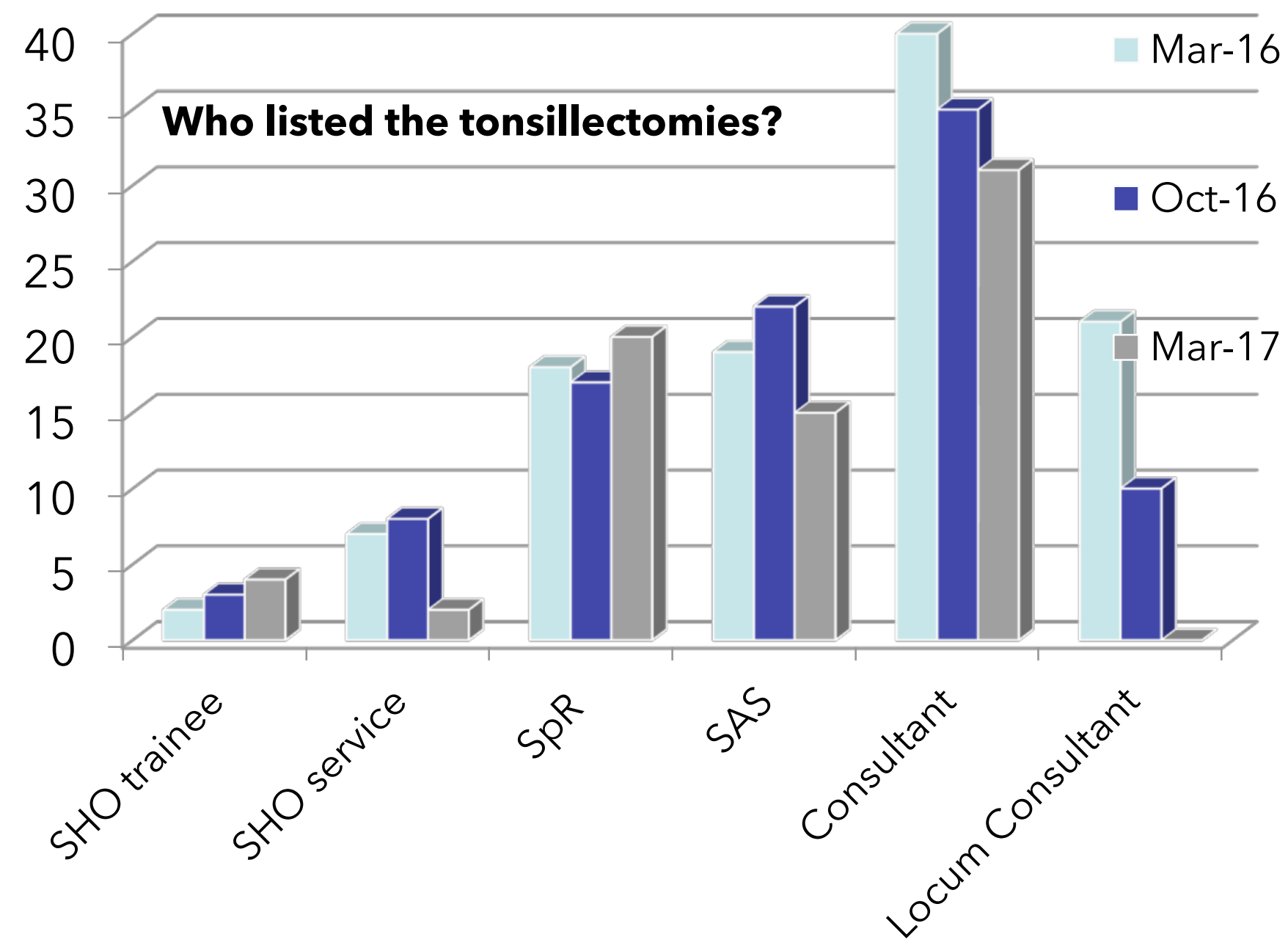

\section{Comments:}

"How do I make the Blueteq form fit this?"

"I'll have to send some histology off, just to justify the Blueteq"

"He wasn't really that urgent, but I had to justify the Blueteq form"

"If you list them for EUA PNS \& grommets, you can do them"

"FNE - adenoidal tissue++. List for EUA PNS +/- adenoidectomy"
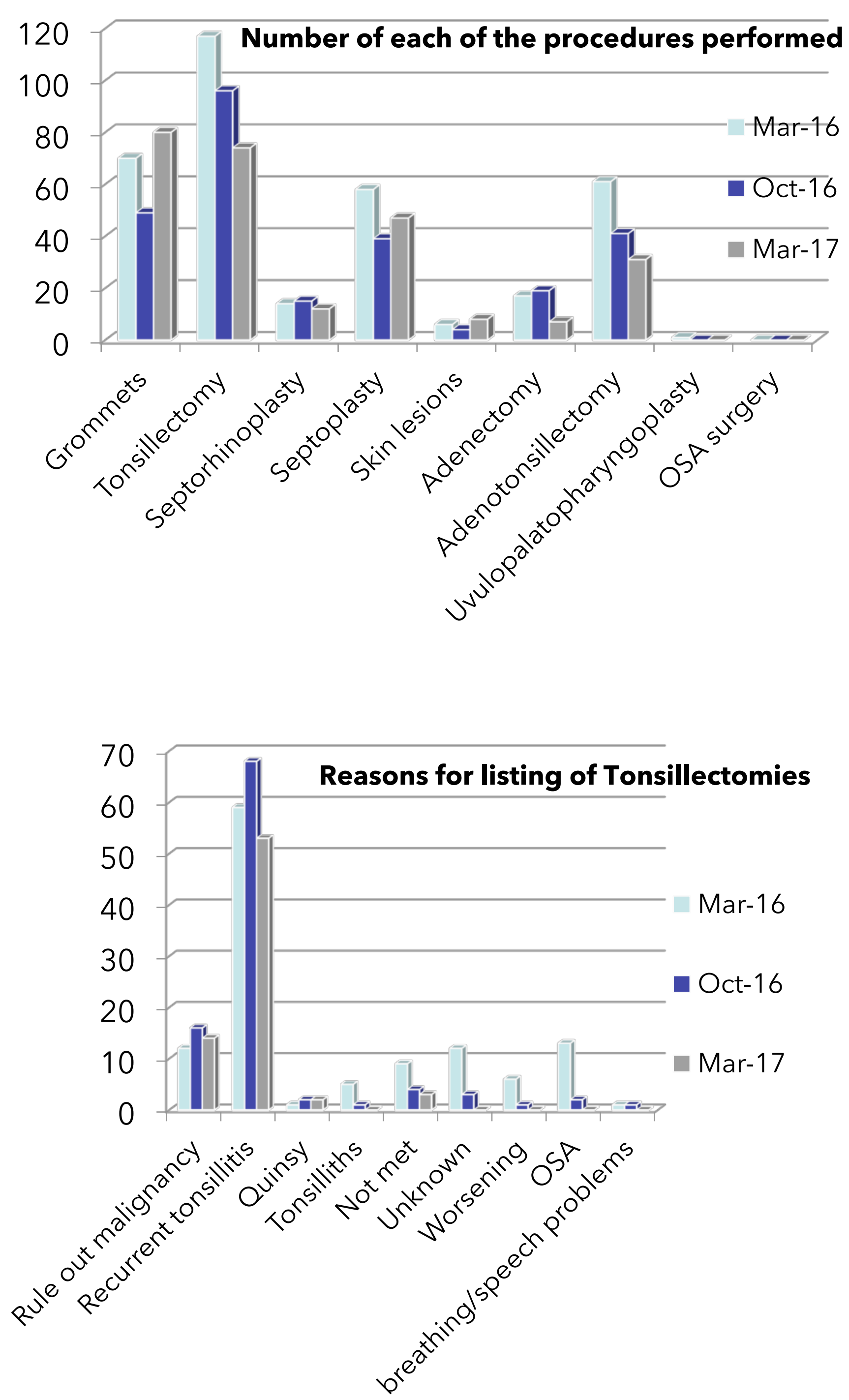